\title{
Reaproveitamento de cinzas de carvão mineral na formulação de argamassas
}

\section{(Reuse of ash coal in the formulation of mortars)}

\author{
J.S. Siqueira, C.A. G. Souza, J.A.S. Souza \\ Programa de Pós Graduação em Engenharia Química, Universidade Federal do Pará, \\ UFPA/PPEQ, Belém, PA 66075-110 \\ jacilene_s@yahoo.com.br,celioag@ufpa.br,jass@ufpa.br
}

\begin{abstract}
Resumo
Este trabalho tem como objetivo o estudo da incorporação de cinzas provenientes da combustão do carvão mineral em caldeiras de leito fluidizado, na produção de argamassas, em substituição parcial do cimento. Foram elaborados corpos de prova utilizando-se os cimentos Portland com as especificações CPII-E-32 de características normais e areia de classificação abaixo da malha 100. Foram preparadas misturas na proporção 4 partes de agregado e 1 parte de cimento, com a inserção de cinzas nas proporções $0,10,20,30,40$ e $50 \%$. A argamassa foi desenvolvida em misturador e a moldagem foi feita em moldes de $5 \mathrm{~cm}$ x $10 \mathrm{~cm}$. Foi analisado o comportamento de resistência à compressão após 28 dias. A resistência diminui conforme o aumento da porcentagem de cinzas. Foram feitas análises complementares de difração de raios X e constatou-se que a substituição desse resíduo pode ser feita com sucesso em argamassas com teores de até $30 \%$.
\end{abstract}

Palavras-chave: cinza de carvão mineral, argamassa, resistência à compressão, difração de raios X.

\begin{abstract}
This paper aims to study the ash incorporation from the combustion of coal in fluidized bed boilers, in production of mortar, replacing part of cement. Specimens were prepared using Portland cement to the specifications CPII-E-32 of normal characteristics and classification of sand below 100 mesh. Blends in the 4:1 ratio, that is, 4 parts of aggregate to 1 part of cement, with insertion of ashes in the proportions 0,10,20,30, 40 and 50\%. The mortar was developed in mixing and casting was made in a mold of $5 \mathrm{~cm} \times 10 \mathrm{~cm}$. The behavior of compressive strength was evaluated after 28 days; the strength decreases with increasing percentage of ash. Additional analysis was carried out by X-ray diffraction, and it was found that the substitution of this waste can be successfully used in mortars with blends of up to $30 \%$.
\end{abstract}

Keywords: ash coal, mortar, compressive strength, X-ray diffraction.

\section{INTRODUÇÃO}

A geração de subprodutos é uma das conseqüências de qualquer processo industrial. No Brasil, com o crescimento do setor industrial, tornam-se maiores as quantidades destes rejeitos surgindo a constante preocupação com o descarte não adequado. Contudo, comumente buscam-se soluções eficazes para a diminuição dos impactos ambientais e redução de custos. O aproveitamento de resíduos industriais destinados a construção civil é uma alternativa viável do ponto de vista técnico e econômico, pois tende a minimizar ou até mesmo eliminar estes resíduos. O uso de novos materiais na indústria da construção civil, sobretudo os materiais provenientes de resíduos industriais, tem sido cada vez mais intenso. Existem pelo menos duas razões básicas que induzem a essa realidade: a primeira deve-se ao grande volume de materiais que a construção civil demanda, e a segunda é devido à vinculação do tema, à valorização e ao uso de resíduos industriais no setor da construção civil e na área de proteção ambiental [7]. O aproveitamento de resíduos industriais como matéria-prima destinada à construção civil vem se consolidando como uma alternativa viável do ponto de vista técnico, ambiental e econômico, pois tende a minimizar ou até mesmo eliminar estes resíduos.

Cinzas volantes são subprodutos resultantes da combustão do carvão mineral em caldeiras. Para as empresas geradoras, este resíduo torna-se um problema em relação ao descarte final. Desta forma se faz necessário estudar aplicações tecnológicas para essas cinzas. A reutilização de cinzas na formulação de argamassas e concretos é uma alternativa interessante, visto que este material possui atividade pozolânica. Pozolanas são materiais silicosos 
ou silicoaluminosos que, por si sós, possuem pouca ou nenhuma atividade aglomerante, mas que quando finamente divididos e na presença da água, reagem com o hidróxido de cálcio à temperatura ambiente para formar compostos com propriedades aglomerantes [2]. As pozolanas freqüentemente são mais baratas do que o cimento Portland que elas substituem, e possuem a característica de uma hidratação lenta, e sua baixa taxa de desenvolvimento de calor; isto é de grande importância na construção em massa e é por isso que o cimento Portland-pozolana ou uma substituição parcial do cimento Portland pela pozolana é bastante utilizado [6].

Os cimentos podem ser definidos como substâncias adesivas capazes de unir fragmentos ou massas de um material sólido a um compacto. Tal definição abraça um grande número de substâncias diferentes que têm pouco em comum umas com as outras, mas sua adesividade e a importância técnica e científica muito desigual de membros diferentes da classe tende a provocar uma restrição da designação a um grupo de substâncias adesivas, isto é, aos materiais plásticos empregados para produzir adesão entre pedras, tijolos, etc. na construção de edifícios e trabalhos de engenharia [4]. É um material pulvurulento, constituído de silicatos e aluminatos de cálcio com inúmeras propriedades e características, que ao serem misturados com água, hidratam-se, sendo capazes de desenvolver elevada resistência mecânica ao longo do tempo. Foi observado que dependendo da composição química e distribuição do tamanho de partículas, vários resíduos industriais podem ser usados em argamassas para a construção civil, seja em substituição parcial ao cimento ou ao agregado miúdo [3]. Diversos estudos vêm apresentando sucessos na utilização de resíduos inorgânicos para a produção de argamassas, evidenciando sua adequabilidade como matérias-primas alternativas para a construção civil. Neste contexto, este trabalho tem por objetivo estudar a viabilidade de utilização de cinzas volantes, obtidas na queima do carvão mineral em caldeiras de leito fluidizado de uma refinadora de alumina localizada no estado do Pará, como materiais alternativos para a produção de argamassas.

\section{MATERIAIS E MÉTODOS}

Foi produzida uma argamassa de referência (sem adição de cinza) para comparação com argamassas adicionadas de cinzas de carvão mineral em substituição ao cimento. Após a caracterização dos materiais, foram realizadas misturas, com e sem adição de cinza, utilizando um misturador mecânico, localizado na Usina de Materiais da Universidade Federal do Pará. Foi definida a relação água/aglomerante (a/ ag) de 0,8. Foi produzida uma argamassa de referência e, posteriormente a cinza substituiu o cimento nos seguintes teores: $10 \%, 20 \%, 30 \%, 40 \%$ e $50 \%$. Após o preparo, as misturas foram colocadas em moldes metálicos cilíndricos de tamanho $50 \mathrm{~mm}$ de diâmetro e $100 \mathrm{~mm}$ de altura para confecção dos corpos de prova, conforme estabelecidos na norma ABNT NBR 7215. Após 24 horas os corpos de prova foram retirados dos moldes para cura em temperatura

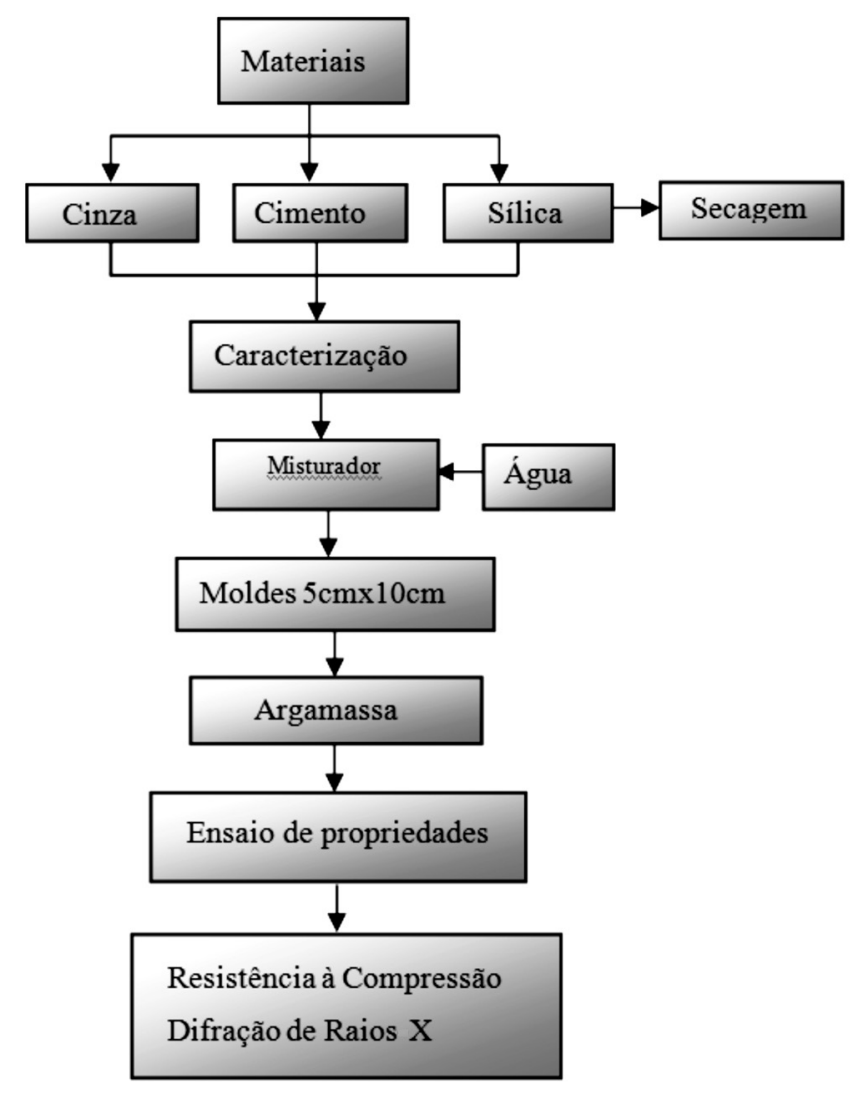

Figura 1: Fluxograma do processo.

[Figure 1: Particle size analysis of silica.]

ambiente pore 28 dias. $\mathrm{O}$ traço utilizado foi determinado em 1:4, devido este traço ser utilizado comercialmente em argamassas de assentamento.

O processo experimental compreendeu a caracterização dos materiais: cinza, cimento e sílica. Além de ensaios de resistência à compressão e difração de raios X. A Fig. 1 apresenta o fluxograma do processo experimental.

Os ensaios de resistência à compressão das argamassas formuladas foram feitos aos 28 dias de acordo com a norma ABNT NBR 7215 em uma prensa CBR manual sem anel dinamométrico Solotest. Para as análises da cinza e dos corpos de prova foi feita a preparação, que consistiu na pulverização em gral e pistilo. Posteriormente as amostras foram submetidas à análise por difração de raios $\mathrm{X}$ em difratômetro Philips PW 3710 com fonte de radiação de cobre e ângulo de difração variando de 4 a $60^{\circ}$.

Foram utilizados os seguintes materiais: resíduos de carvão mineral - as cinzas utilizadas nesta pesquisa são provenientes de uma empresa refinadora de alumina do estado do Pará. São geradas a partir da combustão do carvão mineral em caldeiras de leito fluidizado circulante. Na cinza foram feitas análises por difração de raios X e fluorescência de raios X; além disso, foi feita a análise granulométrica deste resíduo, cujo resultado a caracteriza como cinza volante; cimento - tipo Portland CP II E32 da marca Poty. A Tabela I mostra suas principais propriedades segundo o fabricante. 
Tabela I - Propriedades do cimento.

[Table I - Properties of the cement.]

\begin{tabular}{ll}
\hline \multicolumn{1}{c}{ Propriedades } & \multicolumn{1}{c}{ Resultado } \\
\hline Resistência à compressão aos 28 dias & $\geq 32 \mathrm{MPa}$ \\
Tempo de pega $(\mathrm{h})$ & Início: $\geq 1$ \\
Finura: resíduo na peneira $75 \mathrm{~mm}(\%)$ & $\leq 12,0$ \\
\hline
\end{tabular}

A sílica é a mesma comercializada na região de Belém, PA, sendo submetida a secagem em estufa por 24 h. Em seguida foi feita análise granulométrica, pois será utilizado o material que estiver abaixo ma malha \#100.

\section{RESULTADOS E DISCUSSÃO}

\section{Cinza volante}

A Fig. 2 representa a caracterização do material, por difração de raios $\mathrm{X}$, mostrando a presença de três minerais: calcita, quartzo e anidrita.

Foi feita a análise química por fluorescência de raios $\mathrm{X}$,

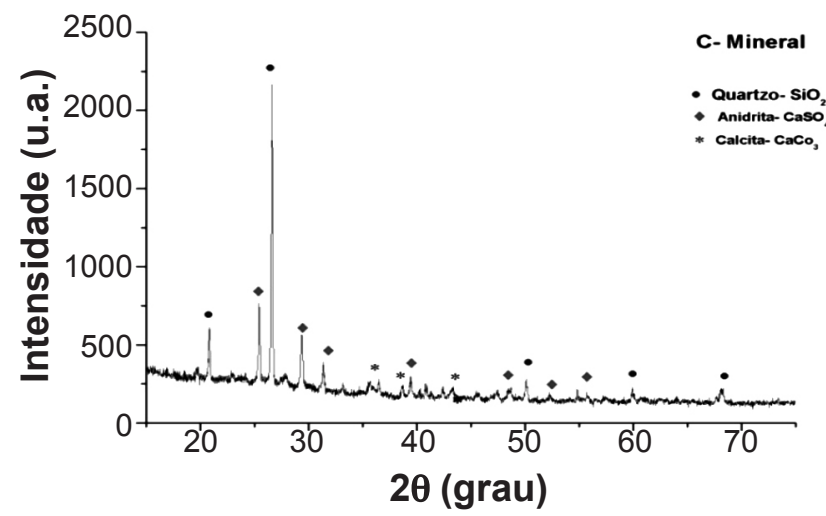

Figura 2: Difratograma de raios $\mathrm{X}$ da cinza volante.

[Figure 2: X-ray diffraction pattern of fly ash.]

Tabela II - Análise química da cinza volante. [Table II - Chemical analysis of the fly ash.]

\begin{tabular}{cc}
\hline Composto & Concentração (\%) \\
\hline $\mathrm{Al}_{2} \mathrm{O}_{3}$ & 13,69 \\
$\mathrm{CaO}$ & 14,05 \\
$\mathrm{Fe}_{2} \mathrm{O}_{3}$ & 5,03 \\
$\mathrm{MgO}$ & 1,45 \\
$\mathrm{~K}_{2} \mathrm{O}$ & 1,2 \\
$\mathrm{Na}_{2} \mathrm{O}$ & 0,75 \\
$\mathrm{MnO}$ & 0,04 \\
$\mathrm{SiO}_{2}$ & 33,80 \\
$\mathrm{SO}_{3}$ & 7,33 \\
$\mathrm{PF}^{*}$ & 21,69 \\
$\mathrm{Total}$ & 99,03 \\
\hline
\end{tabular}

Tabela II, revelando que a cinza é composta, em sua maioria, por sílica $(33,8)$, calcário $(14,0)$ e alumina $(13,7)$, o que a caracteriza como um material pozolânico.

A Tabela III e a Fig. 3 apresentam a análise granulométrica da cinza volante.

Tabela III - Análise granulométrica da cinza volante. [Table III - Particle size analysis of the fly ash.]

\begin{tabular}{ccccc}
$\begin{array}{c}\text { Malha } \\
\text { \#Tyler }\end{array}$ & $\begin{array}{c}\text { Abertura } \\
(\mu \mathrm{m})\end{array}$ & $\begin{array}{c}\text { M. retida } \\
(\mathrm{g})\end{array}$ & $\begin{array}{c}\text { RA } \\
(\%)\end{array}$ & $\begin{array}{c}\text { PA } \\
(\%)\end{array}$ \\
\hline 100 & 150 & 1,36 & 0,68 & 99,32 \\
150 & 106 & 9,86 & 5,61 & 94,39 \\
250 & 63 & 40,29 & 25,76 & 74,24 \\
325 & 45 & 24,91 & 38,21 & 61,79 \\
400 & 38 & 22,27 & 49,35 & 50,65 \\
-400 & -38 & 101,31 & 100 & 0 \\
Dimensão máxima característica & $150 \mu \mathrm{m}$ \\
Dimensão mínima característica & $<38 \mu \mathrm{m}$ \\
\multicolumn{4}{l}{ Módulo de finura } \\
\hline
\end{tabular}

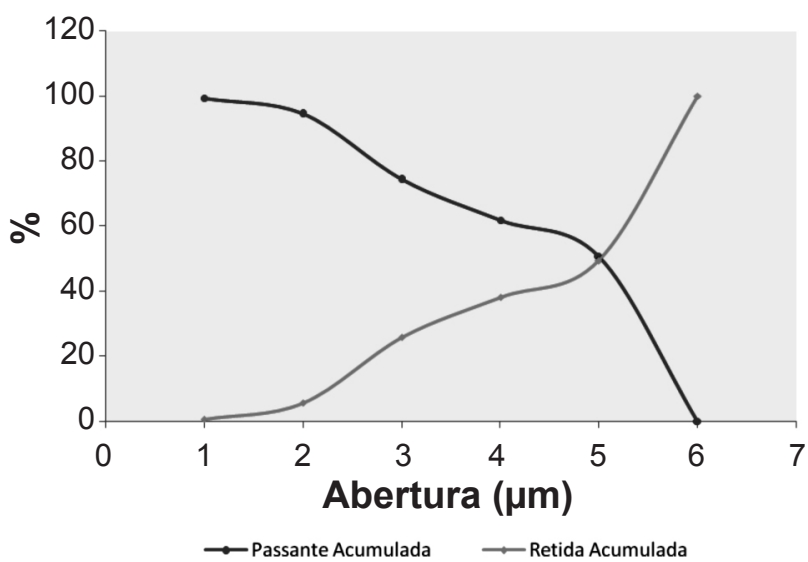

Figura 3: Análise granulométrica da cinza volante.

[Figure 3: Particle size analysis of the fly ash.]

Sílica

A Tabela IV e a Fig. 4 mostram a análise granulométrica da sílica empregada.

\section{Resistência à compressão}

A Fig. 5 mostra os resultados de resistência a compressão, aos 28 dias, das argamassas produzidas.

Com o aumento do teor de cinza volante em substituição ao cimento houve uma redução da resistência nas argamassas curadas a temperatura ambiente. Este comportamento indica que a substituição parcial do cimento por cinzas volantes influencia na resistência a compressão. Estudos observaram melhoras na resistência à compressão simples de argamassas quando da utilização de pozolanas em substituição parcial 
Tabela IV - Análise granulométrica da sílica.

[Table IV - Particle size analysis of silica.]

\begin{tabular}{ccccc}
\hline \#Tyler & $\begin{array}{c}\text { abertura } \\
(\mu \mathrm{m})\end{array}$ & $\begin{array}{c}\text { massa retida } \\
(\mathrm{g})\end{array}$ & $\begin{array}{c}\text { \% retida } \\
\text { acumulada }\end{array}$ & $\begin{array}{c}\text { \% passante } \\
\text { acumulada }\end{array}$ \\
\hline 14 & 1168 & 20,11 & 3,35 & 96,65 \\
28 & 589 & 49,62 & 8,27 & 88,38 \\
35 & 420 & 126,10 & 21,02 & 67,36 \\
42 & 351 & 55,98 & 9,33 & 58,03 \\
65 & 208 & 187,38 & 31,23 & 26,8 \\
100 & 147 & 62,71 & 10,45 & 16,35 \\
-100 & -147 & 98,1 & 16,35 & 0 \\
Dimensão máxima característica & \multicolumn{2}{c}{$1168 \mu \mathrm{m}$} & \\
Dimensão mínima característica & \multicolumn{2}{c}{$<147 \mu \mathrm{m}$} \\
Módulo de finura & \multicolumn{4}{c}{2,46} \\
\hline
\end{tabular}

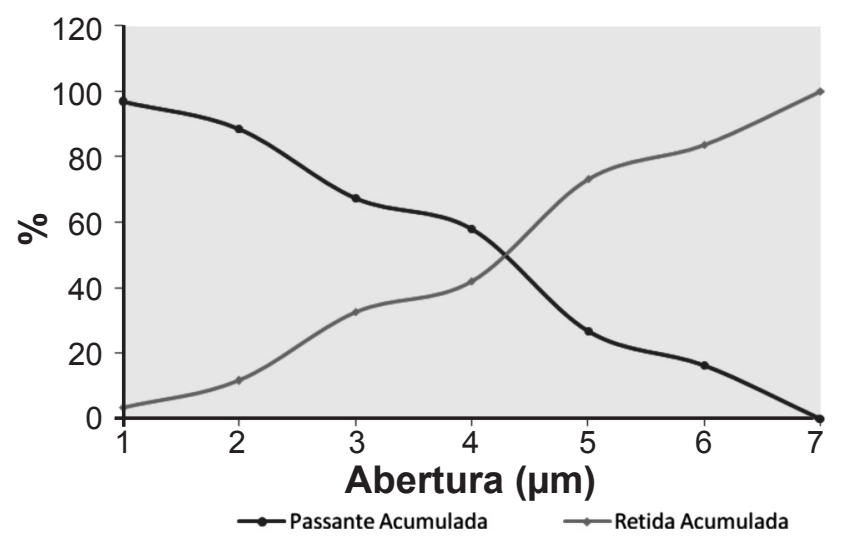

Figura 4: Análise granulométrica da sílica.

[Figure 4: Process flowchart.]

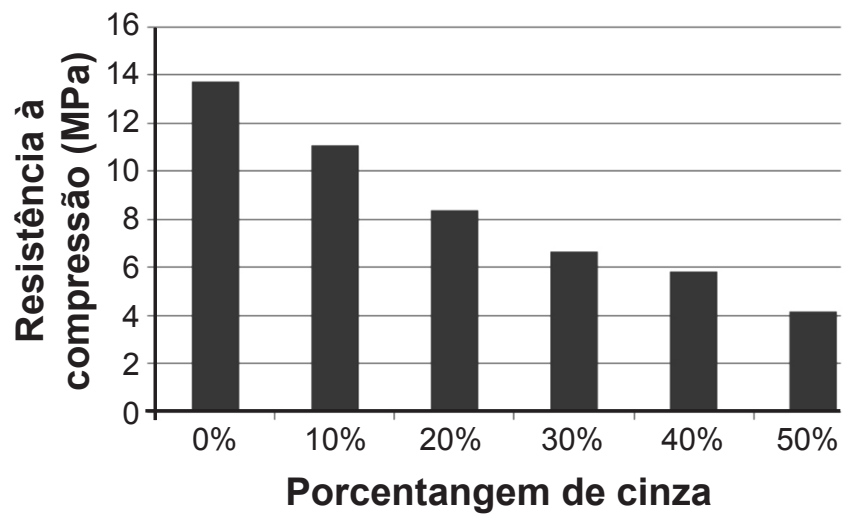

Figura 5: Resistência à compressão após 28 dias [Figure 5: Compressive strength after 28 days.]

do cimento, sendo possível substituir o cimento em teores de até $40 \%$ [5,6]. Nesse sentido verifica-se que a substituição parcial do cimento por materiais com características pozolânicas vem ao encontro dos resultados encontrados na literatura, possibilitando a melhora nas características mecânicas das argamassas produzidas

Foi realizada a análise de fases cristalográficas das argamassas por meio de difração de raios X. Esta análise mostra uma redução das fases principais do cimento (silicatos e aluminatos) com o aumento no teor de cinza, devido ao aumento do teor de sílica livre. Isto influencia na diminuição das propriedades mecânicas das argamassas, o que esclarece a queda na resistência à medida que se aumenta o teor de cinza. A Fig. 6 apresenta os difratogramas das argamassas produzidas.

As fases cristalinas observadas nas amostras são similares às presentes nas matérias primas empregadas na formulação das argamassas. A portlandita $\left(\mathrm{Ca}(\mathrm{OH})_{2}\right)$ foi totalmente consumida nos teores de $40 \%$ e $50 \%$. Não foram observados picos relacionados ao silicato de cálcio hidratado (CSH), produto da reação pozolânica entre os resíduos e a cal, o que está provavelmente relacionado à baixa cristalinidade do silicato formado.

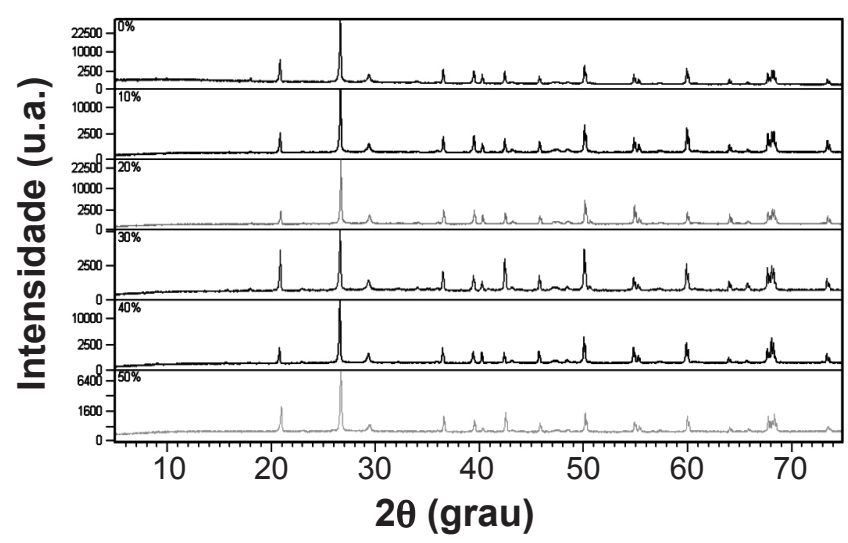

Figura 6: Difratogramas de raios $\mathrm{X}$ das argamassas após 28 dias. $\mathrm{P}=$ Portlandita, $\mathrm{Q}=$ Quartzo, $\mathrm{C}=$ Calcita.

[Figure 6: X-ray diffraction patterns of mortars after 28 days. $P=$ Portlandite, $Q=$ Quartz, $C=$ Calcite.]

\section{CONCLUSÕES}

A metodologia de avaliação de cinzas volantes de caldeiras de leito fluidizado como substituinte ao aglomerante de estudo deste trabalho forneceu valores de 
desempenho satisfatórios. A resistência à compressão, aos 28 dias, das argamassas com adição de cinzas foi menor que o traço de referência. $\mathrm{O}$ aumento no teor de cinza na mistura é proporcional a redução de resistência á compressão dos corpos de prova devido à redução nos componentes básicos do cimento, como silicatos e aluminatos de cálcio. A análise de difração de raios $\mathrm{X}$ mostrou a queda do componente hidróxido de cálcio (Portlandita) com o aumento do teor de cinzas, sendo que em $40 \%$ e $50 \%$ houve o seu desaparecimento. As argamassas contendo cinza apresentaram picos menores de hidróxido de cálcio em relação ao de referência, pois o desenvolvimento das reações pozolânicas é feita com a combinação da sílica presente na cinza e o hidróxido de cálcio liberado durante a hidratação dos silicatos do cimento. A substituição do aglomerante por resíduo na produção de argamassas pode ser efetuada com sucesso em teores de até $30 \%$. Os ensaios mostraram que a produção de argamassas contendo cinza de carvão mineral é interessante para a indústria de construção civil não só na parte técnica como também em aspectos econômicos e ambientais. A cinza possui pouco ou nenhum valor comercial, a fabricação de argamassas à base desse material viabiliza a economia de consumo de materiais além de diminuir a estocagem desse resíduo.

\section{REFERÊNCIAS}

[1] Associação Brasileira de Normas Técnicas, NBR 7215, Cimento Portland - Determinação da Resistência à Compressão, Rio de Janeiro, RJ (1996).

[2] Associação Brasileira de Normas Técnicas, NBR 12653, Materiais pozolânicos - Especificação, Rio de Janeiro, RJ (1992).

[3] E. Gemelli, S. Lourenci, M. V. Folgueras, N. H. Almeida Camargo, Cerâmica 50, 316 (2004) 336.

[4] F. M. Lea, The chemistry of cement and concrete, Edward Arnold, London, Inglaterra (1970).

[5] J. Farias Filho, J. S. Rolim, R. D. Toledo Filho. Rev. Bras. Eng. Agr. Amb. 4, 3 (2000) 437.

[6] M. A. Coimbra, W. N. dos Santos, M. R. Morelli, Cerâmica 48, 306 (2002) 300.

[7] P. V. Margon, Influência do uso de cinzas de carvão mineral de termoelétricas em argamassas de revestimentos: dosagem por curvas granulométricas, Diss. Mestrado, Departamento de Engenharia Civil, UFSC, Florianópolis, SC (2002) 127p.

(Rec.06/05/2011, Rev.31/07/2011, Ac. 01/11/2011) 